\title{
Ecotoxicological evaluation of chemical indicator substances present as micropollutants in laboratory wastewaters
}

\author{
Silva A. ${ }^{1}$, Santos L.H.M.L.M. ${ }^{1}$, Antão C. $^{2}$, Delerue-Matos $C^{1}{ }^{1}$ and Figueiredo S.A. ${ }^{1,}$ \\ ${ }^{1}$ REQUIMTE/LAQV, Instituto Superior de Engenharia do Porto, Instituto Politécnico do Porto, Rua Dr. António Bernardino de Almeida, \\ 431, 4200-072 Porto, Portugal \\ 2Equilibrium, Laboratório de Controlo de Qualidade e de Processo, Lda., Praceta João Villaret, n. 183, 4460-337 Senhora da Hora, \\ Portugal.
}

Received: 21/11/2015, Accepted: 21/02/2017, Available online: 03/03/2017

*to whom all correspondence should be addressed:

e-mail: saf@isep.ipp.pt

\begin{abstract}
Laboratories produce a large volume of wastewaters containing different chemical indicators, organic species for which there is no complete knowledge about their effects in the aquatic environment.

The aim of this work was to evaluate the ecotoxicity of four chemical indicator substances commonly used in titrations (sodium diphenylamine-4-sulfonate, phenolphthalein, methyl orange, and eriochrome black T) by applying two distinct bioassays that evaluated the growth inhibition of the microalga Chlorella vulgaris and the acute immobilization of the microcrustacean Daphnia magna.
\end{abstract}

All the indicators showed growth inhibition rates in the chronic test performed with the alga $C$. vulgaris. Only phenolphthalein and eriochrome black- $T$ showed high immobilization rates on the acute test for $D$. magna. $C$. vulgaris showed higher sensitivity to the chemical indicators tested than $D$. magna. Eriochrome black T was the most toxic for both test organisms and, according to the effective concentration that causes inhibition on 50\% of $C$. vulgaris population, it can be considered as "highly toxic to aquatic organisms". Phenolphthalein and methyl orange may be classified as "toxic to aquatic organisms" and sodium diphenylamine-4-sulfonate is the least toxic, only being considered as "harmful".

This work increases the awareness of the hazardous effects of these chemical indicators and reinforces the need of improved solutions to manage and treat laboratory effluents.

Keywords: Chemical indicators, Chlorella vulgaris, Daphnia magna, ecotoxicity, environment, laboratory wastewaters.

\section{Introduction}

Nowadays there is a growing concern about the waste management of laboratory effluents, since this practise is essential towards the sustainability of the environment.

The recovery of organic solvents and the removal of inorganic species, such as metals, are the main focus of laboratory wastewater treatment. But some organic compounds are present in low concentrations and, despite having an insignificant contribution to the organic load of the effluents, like chemical indicators, they may pose risk to aquatic environment if they are not properly removed.

Nevertheless the evolution of analytical techniques, classic methods of titration using chemical indicators remain in most analytical laboratories since they are often recommended as standard methods, e.g. determination of hardness and alkalinity in waters (Rice et al., 2012). Among the chemical indicators most widely used are sodium diphenylamine-4-sulfonate, phenolphthalein, methyl orange and eriochrome black $T$, which were selected for this study.

Sodium diphenylamine-4-sulfonate indicator is used in oxidation-reduction titrations. It has a colourless reduced form and a red-violet oxidized form. One of its main application is the dichromate titration (Mendham et al., 2002; Harris, 1995). Phenolphthalein and methyl orange are chemical indicators commonly used in acid-base titrations, namely for standardization of solutions (Mendham et al., 2002) and alkalinity determination (Rice et al., 2012). At pH less or equal to 8 phenolphthalein exists in the colourless form, between 8 and 10 phenolphthalein exists as a mixture of the bezenoid form (colourless) and the quinonoid form (red-pink colour), and for higher $\mathrm{pH}$ values the colourless carbinol is formed (Kunimoto et al., 2001). Methyl orange is a non-biodegradable sulphonated azo dye, which has a red acid form for $\mathrm{pH}$ values below 2.9 and changes to an orange basic form at $\mathrm{pH}$ higher than 4.6 (Mendham et al., 2002). Eriochrome black $T$ is one of the most important azo indicators used in complexation titrations applied in the quantification of various metals as, for example $\mathrm{Ca}, \mathrm{Mg}, \mathrm{Mn}, \mathrm{Cd}, \mathrm{Hg}, \mathrm{Pb}, \mathrm{Cu}, \mathrm{Al}, \mathrm{Fe}, \mathrm{Ti}, \mathrm{Co}, \mathrm{Ni}$ and Pt (Masoud et al., 2002) and hardness determination (Mendham et al., 2002). It is blue in its protonated form and red when it forms a complex with calcium or other metals. 
Toxicity assessment of effluents is essential in order to provide data on their potential harmful effects to the environment (Sahu et al., 2008). However, ecotoxicological data for chemical indicators is sparse or even absent. According to the material safety data sheet of methyl orange, phenolphthalein and eriochrome black $\mathrm{T}$, it is only indicated that their discharge into the environment must be avoided (SDS, 2012, 2014a, 2014b). For instance, methyl orange showed to be toxic for the earthworm Eisenia andrei, and inhibited the germination of Bromus ramosus seeds (Trabelsi et al., 2013). On the other hand, phenolphthalein exhibited an $\mathrm{EC}_{50}$ (effective concentration that causes effects in $50 \%$ of the population) higher than $4.34 \mathrm{mg} \mathrm{l}^{-1}$ (48 $\mathrm{h}$ test) for Daphnia magna (SDS, 2014a) and an $\mathrm{EC}_{50}$ for algae (Desmodesmus subspicatus) growth inhibition of $2.5 \mathrm{mg} \mathrm{l}^{-1}$ (72 h test) (SDS, 2014a). Phenolphthalein was also pointed out as a substance of very high concern because of its carcinogenic, mutagenic or toxic for reproduction properties, being included by European Chemicals Agency (ECHA) as a candidate in the list of substances to be taken into account for inclusion in the REACH regulation list of substances of Very High Concern (ECHA, 2011). The indicator eriochrome black T showed toxicity for bacteria and the fish fathead minnow (Pimephales promelas). For the former an $\mathrm{EC}_{50}$ between 10 and $100 \mathrm{mg} \mathrm{l}^{-1}$ was reported, while the later presented a LC 50 of $6 \mathrm{mg} \mathrm{l}^{-1}$ (96 h test) (SDS, 2014b).

Given the scarcity of ecotoxicological data relatively to chemical indicators, standard bioassays were performed at two different trophic levels, using the alga Chlorella vulgaris and the crustacean Daphnia magna, to evaluate the potential toxic effects of the chemical indicators methyl orange, phenolphthalein, sodium diphenylamine-4sulfonate, and eriochrome black T. These two species of organisms were selected since they are representative of primary producers ( $C$.vulgaris) and primary consumers (D. magna). Moreover, algae play an important role in the equilibrium of aquatic ecosystems, being the first level of the trophic chain. Therefore, any perturbation in their dynamics might affect the ecosystem upper levels. Algae are also very sensitive to changes in their environment and present the advantage of having a short life cycle, allowing the evaluation of toxic effects over several generations (Pelczar et al., 1993; Shaw and Chadwick, 1998). The unicellular green alga $C$. vulgaris, often used in ecotoxicological studies (Hernández-Zamora et al., 2014; Santos et al., 2010), was used in the present work due to its high sensitivity to toxicants (Murray et al., 2010; Silva et al., 2014) and for being widespread in nature (Pelczar et al., 1993), therefore being representative of the algal community. It has been also shown that $C$. vulgaris is useful for the assessment of ecotoxicity in effluents management (Silva et al., 2009). D. magna was chosen since it represents an important link between the lower and higher levels of the nourishing trophic chain. This freshwater organism feeds itself with algae, bacteria, protozoa and organics captured by filtration. Both organisms present some characteristics that make them suitable for ecotoxicity tests, namely their sensitivity, high fecundity, easy culture in laboratory, easy handling and low maintaining costs.
Therefore, these organisms can be a useful tool as prescreening method. Moreover, D. magna is considered a standard test organism in ecotoxicological studies (Guilhermino et al., 2000).

Therefore, the aim of the present work was to evaluate the toxicity of the chemical indicators, methyl orange, phenolphthalein, sodium diphenylamine-4-sulfonate, and eriochrome black $\mathrm{T}$, using two short-term tests, which offer a fast response. With this purpose, a chronic toxicity test $(72 \mathrm{~h})$ for evaluation of $C$. vulgaris growth inhibition and an acute toxicity test ( $48 \mathrm{~h}$ ) on $D$. magna immobilization were performed.

\section{Materials and Methods}

\subsection{Test substances}

All the chemicals used were of pure analytical grade and were purchased from Panreac, except for phenolphthalein and eriochrome black T, which were from Riedel, and absolute ethanol from Carlo Erba. The indicators were prepared as described by Mendham et al. (2002): 0.2\% solution of sodium diphenylamine-4-sulfonate prepared with deionised water; dissolution of $5 \mathrm{~g}$ of phenolphthalein in $500 \mathrm{ml}$ of ethanol followed by addition of $500 \mathrm{~mL}$ deionised water; dissolution of $0.5 \mathrm{~g}$ methyl orange in $1 \mathrm{I}$ of desionised water; dissolution of $0.2 \mathrm{~g}$ eriochrome black $\mathrm{T}$ in $15 \mathrm{ml}$ of triethanolamine and then addition of $5 \mathrm{ml}$ of absolute ethanol, obtaining a final concentration of 10 $\mathrm{g} \mathrm{I}^{-1}$. Tested concentrations (Table 1 ) are within the expected range found in laboratorial wastewaters. Maximum concentrations (Table 1) were estimated based in the average use of indicator and the total volume of wastewater produced.

\subsection{Bioassays}

The ecotoxicity tests were carried out using the freshwater unicellular green alga Chlorella vulgaris and the crustacean cladoceran Daphnia magna. A test with a reference toxicant, potassium dichromate, was performed in order to validate the experimental conditions used.

\subsubsection{Algal growth inhibition test}

The experimental procedure followed the Council Regulation (EC) No 440/2008, which was based in OECD guideline 201 (OECD, 2006) and also EPA-821-R-02-013 guideline (USEPA, 2002).

Each chamber test $(125 \mathrm{~mL})$ received an inoculum of the green alga, C. vulgaris (ACOI $879 \mathrm{OHM}$ ), corresponding to an initial concentration around $10^{5}$ cells $\mathrm{ml}^{-1}$, the chosen volume of indicator solutions and the nutrient medium. In order to adapt the alga to the test conditions and ensure that it is in the exponential growth phase, an inoculum culture was prepared 2-4 days before the beginning of the test. Aseptic techniques were used in the algal cultures handling in order to avoid contamination.

The algae population was exposed in a static system for 72 $\mathrm{h}$ to the selected chemical indicator within the range of concentrations from 0.04 to $250 \mathrm{mg} \mathrm{l}^{-1}$, depending on the test substance (Table 1 ), in order to evaluate its chronic toxicity. A set of five different concentrations, and a control 
was used for each chemical tested. All experiments were made in triplicate. The test was performed at $21 \pm 2{ }^{\circ} \mathrm{C}$ under continuous cool white fluorescent light (4440-8880 lux). Agitation was performed twice daily by hand (USEPA, 2002).

The growth of the population was evaluated in terms of changes in cell density (USEPA, 2002; OECD, 2006), by measuring the optical density (ABS) of each tested condition at $440 \mathrm{~nm}$ (Carvalho et al., 1995), using a Shimadzu UV-2101 PC spectrophotometer (Cell density=1.15E $\left.+7 * A B S, r^{2}=0.996\right)$. For each concentration of chemical indicator tested, the average growth was compared with the respective average growth of the control in order to calculate the inhibition rate obtained. The $\mathrm{pH}$ was also evaluated at the beginning and end of the test and its difference should not exceed 1.5 in the control (OECD, 2006).

The acceptability criteria were met if the final average algal cell density in the control flasks exceeded $10^{6}$ cells $\mathrm{ml}^{-1}$ and the algal cell density among the control replicates did not exceed 20\% (USEPA, 2002). Statistical analysis of data was performed according to EPA guidelines (USEPA, 2002). If the assumptions of normality (Shapiro-Wilk's Test) and homogeneity of variance (Bartlett's Test) were verified analysis of variance techniques were used. A hypothesis testing approach (Dunnett's Procedure), which consists of a parametric test, was used to determine the endpoints NOEC and LOEC; $E_{50}, E_{20}$ and $\mathrm{EC}_{10}$ values were calculated using point estimation techniques (linear interpolation).

\subsubsection{Daphnia acute immobilization test}

D. magna (clone A) was bred in culture medium imitating hard water (ASTM, 2014). The animals were fed with $C$. vulgaris three times a week.

The test was performed according to OECD guideline 202 (OECD, 2004). Juveniles (aged < $24 \mathrm{~h}$ ) from the third to the sixth generation were used as test animals. Five daphnias were used in each test chamber $(10 \mathrm{~mL})$ and a total of five chambers were used for each dilution. Different concentrations, ranging from 0.5 to $250 \mathrm{mg} \mathrm{l}^{-1}$, depending on test substance, (Table 2), were prepared in ASTM hard water (ASTM, 2014).

The experiments were carried out under static conditions and the animals were not fed during the test period ( $48 \mathrm{~h}$ ). All tests were conducted at $20 \pm 2 \circ \mathrm{C}$, and organisms were exposed to a $16 \mathrm{~h}$ light and $8 \mathrm{~h}$ dark cycle.

The measured effect was the organisms' dead recognized as immobilization if the neonates did not resume swimming within the $15 \mathrm{~s}$ observation period, after stimulation by bright light. Statistical evaluation of data was performed by Trimmed Spearman-Karber method for estimating $\mathrm{EC}_{50}$ in toxicity bioassays (Hamilton et al., 1977) as recommended by USEPA (2005) since it is considered better than Probit model.

\section{Results and Discussion}

A plot of the growth inhibition rate of the microalga $C$. vulgaris against concentration was represented for each indicator tested, sodium diphenylamine-4-sulfonate, phenolphthalein, methyl orange and eriochrome black $\mathrm{T}$, and it is shown in Figure 1.

In this study the following toxicity endpoints were estimated: No-Observed-Effect-Concentration (NOEC), Lowest-Observed-Effect-Concentration (LOEC), 10, 20 and $50 \%$ Effective Concentrations ( $E_{10}, E_{20}, E_{50}$ ). The results presented in Table 1 indicate high growth inhibition rates for all the indicators tested, showing $\mathrm{EC}_{50}$ values of 44, 4.7, 4.0 and $0.034 \mathrm{mg}^{-1}$ respectively for sodium diphenylamine-4-sulfonate, phenolphthalein, methyl orange and eriochrome black $\mathrm{T}$.

The chemical indicators methyl orange and eriochrome black T were slightly coloured in the tested concentrations. This might contribute to a decrease in photosynthesis activity leading to an increase of growth inhibition of algae, especially in the case of eriochrome black T. In case of methyl orange colour did not contribute neither to absorbance nor, apparently, to inhibition.

The colour contributed significantly to the optical density of eriochrome black $\mathrm{T}$ solutions above $10 \mathrm{mg} \mathrm{l}^{-1}$, which caused $100 \%$ inhibition of the algal growth. But complete inhibition was also verified almost for all concentrations tested, even when colour was absent. Analysing the effect of the solvents used in its preparation, a $0.034 \mathrm{mg} \mathrm{l}^{-1}$ solution of eriochrome black $\mathrm{T}$ contains $2.9 \mathrm{mg} \mathrm{l}^{-1}$ of triethanolamine and $0.7 \mathrm{mg} \mathrm{l}^{-1}$ of ethanol, it is verified that this effect should be negligible. The EC50 of ethanol (5000 $\mathrm{mg} \mathrm{l}^{-1}$ for a 7 day test with Scenedesmus quadricauda) (SDS, 2015a) is higher than this concentration and therefore it should not contribute to the inhibition verified. And the same occurs with triethanolamine (SDS, 2015b) since its concentration is lower than the EC50 observed for the alga Desmedesmus subspicatus (216 $\left.\mathrm{mg}^{-1}\right)$.

In the preparation of a $4.7 \mathrm{mg} \mathrm{I}^{-1}$ solution of phenolphthalein, ethanol is present in a $371 \mathrm{mg} \mathrm{l}^{-1}$ concentration. Considering that this value is lower than the EC50 (7 d) observed for the alga S. quadricauda (5000 $\mathrm{mg} \mathrm{l}^{-1}$ ) (SDS, 2015a) it is not expected that this solvent contributes to the inhibition verified.

Recent scientific developments have led to a recommendation of abandoning the concept of NOEC and replacing it by regression based point estimates (OECD, 2006), therefore the EC10 and EC20 values were also reported. Table 1 presents the EC50, EC20, EC10, LOEC and NOEC values for comparison. Due to the high growth inhibition verified for eriochrome black $T$ it was not possible to estimate neither NOEC and LOEC, nor EC10 and EC20. The same occurred with EC10 for phenolphthalein. For sodium diphenylamine-4-sulfonate and methyl orange EC10 and EC20 values laid between NOEC and LOEC values and for phenolphthalein EC20 was coincident with NOEC. This comparison indicates that NOEC is a more conservative parameter concerning the estimation of the allowed environmental concentration. 

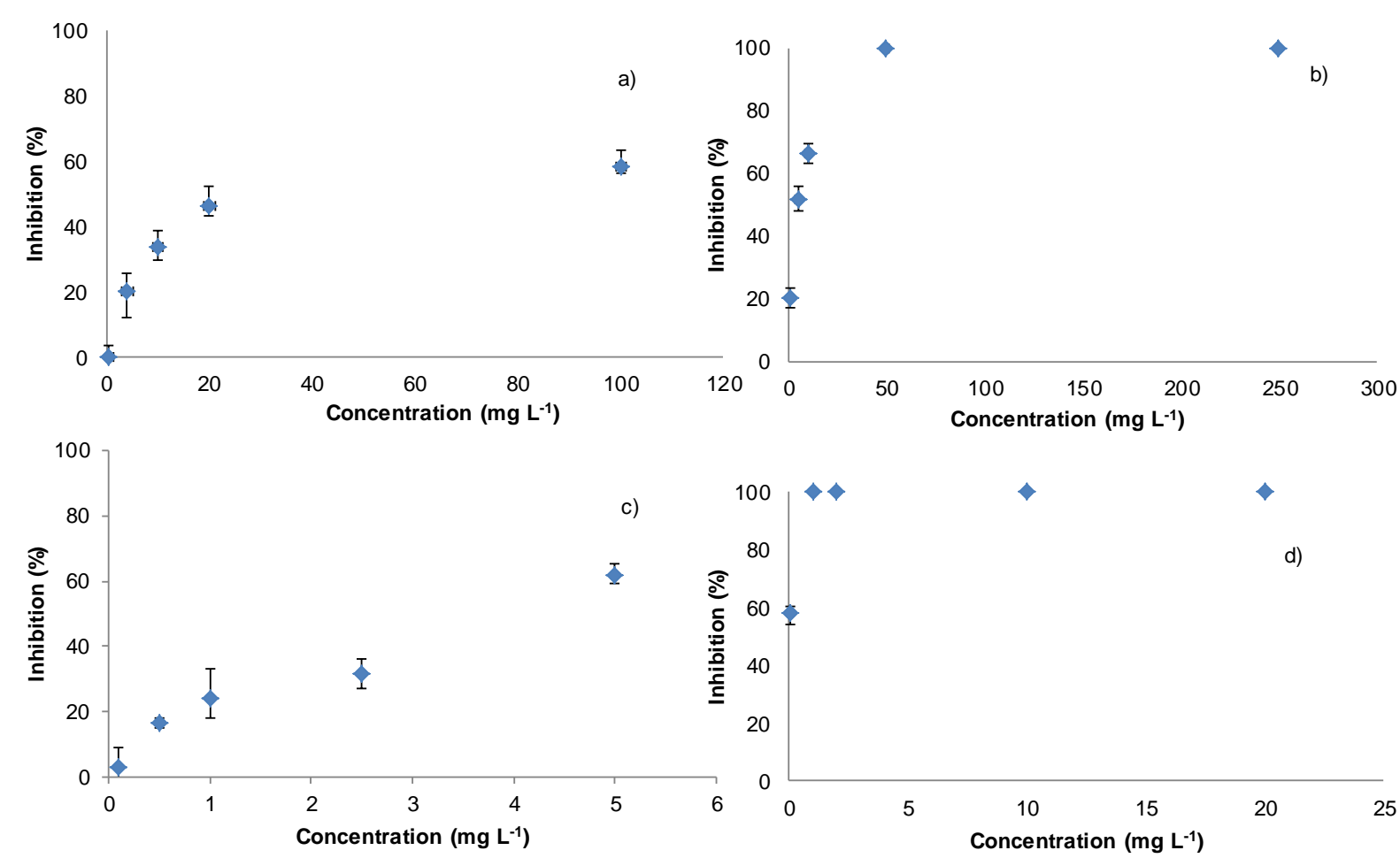

Figure 1. Plots of the growth inhibition rates of the microalgae $C$. vulgaris when exposed to a) sodium diphenylamine-4-sulfonate; b) phenolphthalein; c) methyl orange; d) eriochrome black T

Table 1. Ecotoxicological parameters from the test with $C$. vulgaris and comparison with calculated maximum real values

\begin{tabular}{cccccccc}
\hline Test substance & $\begin{array}{c}\text { NOEC } \\
\left(\mathrm{mg} \mathrm{l}^{-1}\right)\end{array}$ & $\begin{array}{c}\text { LOEC } \\
\left(\mathrm{mg} \mathrm{l}^{-1}\right)\end{array}$ & $\begin{array}{c}\mathrm{EC}_{10} \\
\left(\mathrm{mg} \mathrm{l}^{-1}\right)\end{array}$ & $\begin{array}{c}\mathrm{EC}_{20} \\
\left(\mathrm{mg} \mathrm{l}^{-1}\right)\end{array}$ & $\begin{array}{c}\mathrm{EC}_{50} \\
\left(\mathrm{mg} \mathrm{l}^{-1}\right)\end{array}$ & $\begin{array}{c}\text { Tested range } \\
\left(\mathrm{mg} \mathrm{l}^{-1}\right)\end{array}$ & $\begin{array}{c}\text { Maximum } \\
\text { concentration }\left(\mathrm{mg} \mathrm{l}^{-1}\right) *\end{array}$ \\
\hline $\begin{array}{c}\text { Sodium diphenylamine- } \\
\text { 4-sulfonate }\end{array}$ & 0.4 & 4.0 & 2.4 & 4.0 & 44 & $0.4-100$ & 6 \\
\hline $\begin{array}{c}\text { Phenolphthalein } \\
\text { Methyl orange }\end{array}$ & 1.0 & 5.0 & - & 1.0 & 4.7 & $1.0-250$ & 25 \\
\hline Eriochrome black T & 0.1 & 0.5 & 0.3 & 0.7 & 4.0 & $0.1-5.0$ & 1 \\
\hline
\end{tabular}

*Estimated maximum concentration of the chemical indicator found in laboratorial wastewaters

The test organism, D. magna, behaved differently from C. vulgaris, the plots of the immobilization rate against concentration are represented in Figure 2. Methyl orange and sodium diphenylamine-4-sulfonate did not present an observable effect even for the maximum tested concentrations, respectively $500 \mathrm{mg} \mathrm{l}^{-1}$ and $2000 \mathrm{mg} \mathrm{l}^{-1}$ (Table 2). Immobilization of $D$. magna was only observed for phenolphthalein and eriochrome black T. During the course of exposure, no abnormal behaviour or appearance of D. magna was noticed.
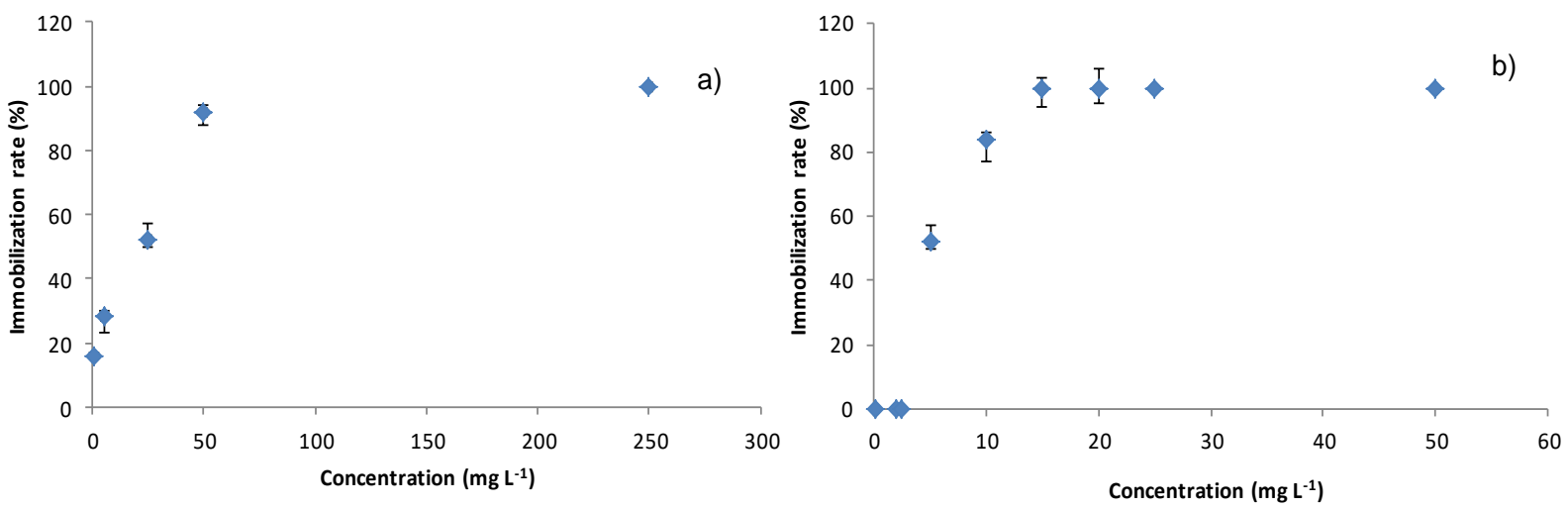

Figure 2. Plots of the immobilization rates of $D$. magna when exposed to: a) phenolphthalein; b) eriochrome black T 
The $E_{50}$ values obtained for phenolphthalein and eriochrome black-T were 13 and $5 \mathrm{mg} \mathrm{l}^{-1}$ respectively, as shown in Table 2 . These values are higher than the calculated real concentration, which indicate that this situation may be dangerous for aquatic ecosystems. In both cases, the solvents used in the preparation of the chemical indicators should not contribute significantly to the toxicity observed for D. magna.

In the preparation of a $13 \mathrm{mg} \mathrm{l}^{-1}$ solution of phenolphthalein, ethanol was present in a $1027 \mathrm{mg} \mathrm{l}^{-1}$ concentration. Considering that this value was lower than the $\mathrm{EC}_{50}$ observed for D. magna, 9268-14221 $\mathrm{mg} \mathrm{l}^{-1}$ (48 h)
(SDS, 2015a), it is not expected that ethanol has contributed significantly to the inhibition verified.

The same occurs with eriochrome black T since a $5 \mathrm{mg} \mathrm{l}^{-1}$ solution of this chemical indicator contains $99 \mathrm{mg} \mathrm{l}^{-1}$ of ethanol and $420 \mathrm{mg} \mathrm{l}^{-1}$ of triethanolamine, which are much lower values than the respective $E_{50}$ for the same organism, 9268-14221 $\mathrm{mg} \mathrm{l}^{-1}$ (48 h) (SDS, 2015a) and 1390 $\mathrm{mg} \mathrm{l}^{-1}(24 \mathrm{~h})$ (SDS, 2015b).

Only the results obtained for phenolphthalein can be compared with those published in literature (SDS, 2014a) and are in agreement with it (>4.34 $\mathrm{mg} \mathrm{l}^{-1}, 48 \mathrm{~h}$ ).

Table 2. Ecotoxicological parameters from the test with $D$. magna and comparison with calculated maximum real values

\begin{tabular}{ccccc}
\hline Test substance & $\mathrm{EC}_{\mathbf{5 0}}\left(\mathrm{mg} \mathrm{l}^{-1}\right)$ & Confidence interval at 95\% $\left(\mathbf{m g ~ l}^{-1}\right)$ & Tested range $\left(\mathbf{m g ~ l}^{-1}\right)$ & $\begin{array}{c}\text { Maximum } \\
\text { concentration* }\left(\mathbf{m g ~ l}^{-1}\right)\end{array}$ \\
\hline $\begin{array}{c}\text { Sodium diphenylamine- } \\
\text { 4-sulfonate }\end{array}$ & - & - & $0.4-2000$ & 6 \\
\hline Phenolphthalein & 13 & $7-26$ & $0.5-250$ & 25 \\
\hline Methyl orange & - & - & $0.1-500$ & 1 \\
\hline Eriochrome black T & 5 & $5-6$ & $0.2-150$ & 33 \\
\hline
\end{tabular}

*Estimated maximum concentration of the chemical indicator found in laboratorial wastewaters

Differences in toxicity between the two selected test organisms could be explained by distinct morphological and metabolic properties between algae and daphnids.

Although the ecotoxicological data of chemical indicators is scarce, a lower EC50 (2.5 mg l-1) was reported for the growth inhibition of the alga $D$. subspicatus when exposed to phenolphthalein for $72 \mathrm{~h}$ (SDS, 2014a), comparatively to the EC50 obtained for $C$. vulgaris $\left(4.7 \mathrm{mg} \mathrm{l}^{-1}\right)$. Moreover, $C$. vulgaris and $D$. magna showed to have higher sensitivity to the eriochrome black $\mathrm{T}$. In the present study $\mathrm{EC}_{50}$ values of 0.034 and $5 \mathrm{mg} \mathrm{l}^{-1}$ where obtained for $C$. vulgaris and D. magna, respectively, while for bacteria and fish reported values for $\mathrm{EC}_{50}$ were of 6 and $10-100 \mathrm{mg} \mathrm{l}^{-1}$, respectively (SDS, 2014b).

Since $C$. vulgaris seems to be more sensitive than $D$. magna, only the algae growth inhibition results were considered to classify the chemical indicators in toxicity categories accordingly to the "Globally harmonized system of classification and labelling of chemicals (GHS)" (United Nations, 2011). Eriochrome black T can be considered as "highly toxic to aquatic organisms" (EC50 $\left.\leq 1 \mathrm{mg} \mathrm{l}^{-1}\right)$; phenolphthalein and methyl orange may be classified as "toxic to aquatic organisms" ( $1<$ EC50 $\left.10 \mathrm{mg} \mathrm{l}^{-1}\right)$; while sodium diphenylamine-4-sulfonate is the least toxic to aquatic organisms, and it is considered as "harmful" $\left(10<E C 50 \leq 100 \mathrm{mg} \mathrm{I}^{-1}\right)$. Although diphenylamine-4sulfonate had shown the lowest toxicity for algae, toxic effects for terrestrial organisms as the earthworm $E$. andrei were reported in literature as well as its potential to inhibit the germination of seeds (Trabelsi et al., 2013).

In all cases NOEC, LOEC, EC10 and EC20 values, obtained for $C$. vulgaris, are lower than the estimated maximum concentrations found in laboratorial wastewaters (Table 1). For phenolphthalein and eriochrome black $T$ the concentration in laboratorial wastes is higher than their EC50 values. Therefore, a safe discharge of these wastes is needed, in order to guarantee environmental concentrations lower than NOEC values. For that an efficient treatment and subsequent dilution are needed, corresponding to a decrease in concentration equivalent to $10,15,18$ and a huge 970 times dilution, respectively for sodium diphenylamine-4-sulfonate, phenolphthalein, methyl orange and eriochrome black T.

\section{Conclusions}

Based on the results of the short-term methods used for ecotoxicity evaluation of chemical indicators, C. vulgaris seems to be more sensitive than $D$. magna. The results of the chronic test performed with the alga $C$. vulgaris indicated high growth inhibition rates for all the indicators tested (sodium diphenylamine-4-sulfonate, phenolphthalein, methyl orange and eriochrome black T). Taking into account the obtained results, eriochrome black T can be considered as "highly toxic to aquatic organisms" (EC50 $\leq 1 \mathrm{mg} \mathrm{l}^{-1}$ ), while phenolphthalein and methyl orange may be classified as "toxic to aquatic organisms" (1<EC50 $\leq 10 \mathrm{mg} \mathrm{l}^{-1}$ ) and sodium diphenylamine-4-sulfonate may be considered as "harmful" $\left(10<\mathrm{EC50} \leq 100 \mathrm{mg} \mathrm{l}^{-1}\right)$, according to the "Globally harmonized system of classification and labelling of chemicals". The NOEC values obtained for $C$. vulgaris were lower than the EC10 values, therefore it should be recommended to consider these values as indicative concentrations for environmental safety.

The ecotoxicological data obtained provides information that could be useful for chemical registration dossiers, substance risk assessment and environmental protection purposes. This work is also a contribution to be aware of the hazardous effects of chemical indicators used in classic titration methods. Due to the complexity of the organic molecules used as chemical indicators, tertiary treatment might be required to get a more efficient treatment of 
laboratory wastewaters. Another alternative is to reduce their use.

Advanced treatments for laboratory effluents containing organic compounds, such as chemical indicators, might be necessary prior to their discharge in order to minimize their impact in the aquatic environment, as well as their toxicity for non-target organisms.

\section{Acknowledgements}

This work was supported by Fundação para a Ciência e Tecnologia/MEC (PIDDAC) and Fundo Europeu de Desenvolvimento Regional (FEDER) through COMPETE Programa Operacional Factores de Competitividade (POFC) under the strategic funding UID/QUI/50006/2013.

\section{References}

ASTM (American Society for Testing and Materials) (2014), Standard Guide for Conducting Acute Toxicity Tests on Test Materials with Fishes, Macroinvertebrates, and Amphibians, ASTM E729 - 96(2014).

Carvalho F., Guilhermino L., Ribeiro R., Gonçalves F. and Soares A.M.V.M. (1995), METIER (modular ecotoxicity tests incorporating ecological relevance). II. Ecotoxicity of poorly water-soluble compounds: Concentration versus dose, Arch. Environ. Contam. Toxicol., 29, 431-434.

ECHA (European Chemicals Agency) (2011), Support document for identification of phenolphthalein as a substance of very high concern because of its CMR properties.

Guilhermino L., Diamantino T., Silva M.C. and Soares A.M.V.M. (2000), Acute toxicity test with Daphnia magna: an alternative to mammals in the prescreening of chemical toxicity?, Ecotoxicol. Environ. Saf., 46, 357-362.

Hamilton M., Russo R. and Thurston R. (1977), Trimmed Spearman-Karber method for estimating median lethal concentrations in toxicity bioassays. U.S. Environmental Protection Agency, EPA/600/J-77/178 (NTIS PB81191918), Washington D.C., USA.

Harris D.C. (1995), Quantitative chemical analysis, W.H. Freeman and Company, New York.

Hernández-Zamora M., Perales-Vela H.V., Flores-Ortíz C.M. and Cañizares-Villanueva R.O. (2014), Physiological and biochemical responses of Chlorella vulgaris to Congo red, Ecotoxicol. Environ. Saf., 108, 72-77.

Kunimoto K.-K., Sugiura H., Kato T., Senda H., Kuwae A. and Hanai K. (2001), Molecular structure and vibrational spectra of phenolphthalein and its dianion, Spectrochim. Acta A, 57, 265-271.

Masoud M.S., Hammud H.H. and Beidas H. (2002), Dissociation constants of eriochrome blue black RC indicators and the formation constants of their complexes with $\mathrm{Fe}(\mathrm{III}), \mathrm{Co}(\mathrm{II})$, $\mathrm{Ni}(\mathrm{II}), \mathrm{Cu}(\mathrm{II}), \mathrm{Zn}(\mathrm{II}), \mathrm{Cd}(\mathrm{II}), \mathrm{Hg}(\mathrm{II})$ and $\mathrm{Pb}(\mathrm{II})$, under different temperatures and in presence of different solvents, Thermochim. Acta, 381, 119-131.

Mendham J., Denney R.C., Barnes J.D. and Thomas M.J.K. (2002), Vogel's textbook of quantitative chemical analysis, Prentice Hall, Pearson Education Limited, UK.

Murray D., Jefferson B., Jarvis P. and Parsons S.A. (2010), Inhibition of three algae species using chemicals released from barley straw, Environ. Technol., 31, 455-466.

OECD (Organisation for Economic Co-operation and Development) (2004), OECD Guidelines for the testing of chemicals: Guideline 202 - Daphnia sp., Acute Immobilisation Test.

OECD (Organisation for Economic Co-operation and Development) (2006), OECD Guidelines for the testing of chemicals: Guideline 201 - Freshwater Alga and Cyanobacteria, Growth Inhibition Test.

Pelczar Jr M.J., Chan E.C.S. and Krieg N.R. (1993), Microbiology concepts and applications, McGraw-Hill, New York, USA.

Rice E.W., Baird R.B., Eaton A.D. and Clesceri L.S. (Eds.) (2012), Standard Methods For the Examination of Water and Wastewater, American Public Health Association, American Water Works Association and Water Environment Federation, USA.

Sahu R.K., Katiyar S., Yadav A.K., Kumar N. and Srivastava J. (2008), Toxicity assessment of industrial effluent by bioassays, Clean - Soil Air Water, 36, 517-520.

Santos L.H.M.L.M., Araújo A.N., Fachini A., Pena A., DelerueMatos C. and Montenegro M.C.B.S.M. (2010), Ecotoxicological aspects related to the presence of pharmaceuticals in the aquatic environment, J. Hazard. Mat., 175, 45-95.

SDS (Safety Data Sheet) (2012), Safety Data Sheet according to Regulation (EC) No. 1907/2006 - Methyl orange. Available from: www.merck-chemicals.com.

SDS (Safety Data Sheet) (2014a), Safety Data Sheet according to Regulation (EC) No. 1907/2006 - Phenolphthalein. Available from: www.merck-chemicals.com.

SDS (Safety Data Sheet) (2014b), Safety Data Sheet according to Regulation (EC) No. 1907/2006 - Eriochrome black T. Available from: www.merck-chemicals.com.

SDS (Safety Data Sheet) (2015a), Safety Data Sheet according to Regulation (EC) No. 1907/2006 - Ethanol. Available from: www.merck-chemicals.com.

SDS (Safety Data Sheet) (2015b), Safety Data Sheet according to Regulation (EC) No. 1907/2006 - Triethanolamine. Available from: www.merck-chemicals.com.

Shaw I.C. and Chadwick J. (1998), Principles of Environmental Toxicology, Taylor \& Francis, London, UK.

Silva A., Figueiredo, S.A., Sales M.G. and Delerue-Matos C. (2009), Ecotoxicity tests using the green algae Chlorella vulgaris - A useful tool in hazardous effluents management, J. Hazard. Mat., 167, 179-185.

Silva A., Santos L.H.M.L.M., Delerue-Matos C. and Figueiredo S.A. (2014), Impact of excipients in the chronic toxicity of fluoxetine on the alga Chlorella vulgaris, Environ. Technol., 35, 3124-3129.

Trabelsi H., Khadhraoui M., Hentati O. and Ksibi M. (2013), Titanium dioxide mediated photodegradation of methyl orange by ultraviolet light, Toxicol. Environ. Chem., 95, 543-558.

United Nations (2011), Globally harmonized system of classification and labelling of chemicals (GHS). United Nations Publications, New York and Geneva.

USEPA (U.S. Environmental Protection Agency) (2005), EPA Science Inventory. Available from: http://cfpub.epa.gov/si/si_public_record_Report.cfm?dirEnt rylD=43308 (accessed on 13/05/2015).

USEPA (United States Environmental Protection Agency) (2002), Short-term methods for estimating the chronic toxicity of effluents and receiving waters to fresh water organisms (EPA821-R-02-013), Washington DC, USA. 